Pobrane z czasopisma New Horizons in English Studies http://newhorizons.umcs.pl Data: 26/04/2023 05:19:51

New Horizons in English Studies 3/2018

\title{
LITERATURE
}

$\infty$

Barbara Kaczyńska

UNIVERSITY OF WARSAW

b.kaczynska92@gmail.com

\section{Metafiction in Children's Literature and its Adaptation on Screen. The Case of Lemony Snicket's A Series of Unfortunate Events}

\begin{abstract}
The paper analyses metafictional aspects of the children's book series A Series of Unfortunate Events by Lemony Snicket as adapted in a 2017 TV series. Focusing on the metaleptic narrator and the receiver's role in the story's interpretation, the analysis shows that the metafiction's manifestation undergoes certain shifts due to the adaptation's status as a secondary work and the underlying existence of the primary text, as well as the visual mode of storytelling predominant in film.
\end{abstract}

Key words: children's literature, metafiction, metalepsis, adaptation, intertextuality, double readership

\section{Introduction}

If translating a message between two languages is a daunting task, then adapting literature to film, which uses a completely different set of signs, seems even less straightforward, especially if the adapter wishes to transform the source text while staying true to its spirit (Andrew 1984, 100). Adaptation always produces a new meaning, stemming not only from the transition from a single-track, predominantly verbal medium to a multi-track and more visually oriented one (Boozer 2008, 1), but also from the intertextuality inherent in the process: the meaning of a given adaptation is always determined by its cultural capacity resulting from a particular symbolic link between the source text and its derivate (Hendrykowski 2013, 268).

That phenomenon is all the more noticeable in the case of a work like $A$ Series of Unfortunate Events by Lemony Snicket, which is known mainly for its style - surpris- 
ingly complex for a children's book - and its ever-present, digression-loving narrator. Most child readers would have no difficulties with recognising Snicket's voice, even though they probably would not know the scholarly term for the phenomenon he represents, i.e., metafiction.

With fiction in its very name, metafiction seems bound with literature, and yet $A \mathrm{Se}$ ries of Unfortunate Events has been adapted twice to film, most recently by Netflix in 2017 as a TV series. However, before analysing the way in which the adapters approached the books' metafictional aspect, it is necessary to discuss its presence in the source text.

\section{The Uses of Metafiction}

The term "metafiction" first appeared in the 1960s, and its meaning changed over time (Currie 1995). At first, it was conceived as a separate genre of experimental fiction, but it soon started to be seen as an aspect of literature that is present, to some degree, in most works of fiction, going as far back as Homer's Odyssey. Waugh defined it as "explor[ing] a theory of fiction through the practice of writing fiction" (Waugh 1984, 2, emphasis in the text). Hutcheon entitled her book about metafiction Narcissistic Narrative (1984), suggesting that the narrative almost obsessively explores its own structure and content. Scholes (1970) emphasised the fact that metafictional prose provides the first criticism of itself. All of those definitions imply that metafiction is fiction that admits, emphasises, and explores its status as fiction. ${ }^{1}$ Its intertextual nature is evident: metafiction can manifest as a secondary (literary) discourse about the storytelling and linguistic structures of literature, or as a hypertext: a transformation of a particular hypotext, such as a parody, an imitation or an allusion (Genette 1982, 13-14; Chanady 1988, 137). In brief, metafiction is a narrative which admits that it is not a transparent presentation of the empirical reality using an objective langue (in the Saussurean sense), but a story which is told by somebody and to somebody, creating its own linguistic microcosm and its own intradiegetic set of references.

Metafiction is often called "writing about writing," but at the same time, it is "writing about reading." The reader is forced to notice and admit the fiction's fictionality, but perhaps paradoxically - he $\mathrm{e}^{2}$ is not alienated (Hutcheon 1984, xiii). On the contrary, he is invited to actively and consciously participate in the game between the storyteller and the receiver. His willingness to engage with and interpret the story is crucial for the story to come to life. Thus, the reader-receiver is far from passive: his participation in the act of the story creation is just as important, if not more so, as the writer-storyteller's.

\footnotetext{
These terms are admittedly problematic, as a text cannot be, strictly speaking, aware of itself; nevertheless, the notion of metafiction as "self-conscious" fiction is well grounded in literature, and therefore it is also used here in a conventional rather than literal sense.

2 Male pronouns used for the sake of brevity.
} 


\section{Metafiction in A Series of Unfortunate Events}

The equal position of the storyteller and of the receiver (or, possibly, the latter's supremacy) is ever present, together with other aspects of metafiction, in A Series of Unfortunate Events by Lemony Snicket (Austin 2013). Published in the early 2000s, it is a series of thirteen highly intertextual novels, conceived as a subversion of stereotypical, idyllic children's literature. The most prominent feature of the series is the focus on the unfortunate, indicated in the very title and exaggerated to the point of becoming humorous. The protagonists are orphans straight from a Victorian chapbook, persecuted by evil Count Olaf who wants to steal their fortune. The plot is simplistic at first, but it becomes more and more complicated from the fifth book onwards, with the introduction of a secret fire-fighting organization (hiding under the acronym V.F.D.), secret codes, secret headquarters, secret identities, and other secrets, some of which are never explained. The narrative frequently alludes to such authors as Charles Baudelaire (who gave his name to the protagonists), Herman Melville, or T.S. Eliot. On almost every page, it emphasises its fictional status with a striking lack of specificity as to the time and place in which it is set, with intentionally stilted dialogue, and most of all, with the elusive but ever-present figure of Lemony Snicket.

At first glance, Lemony Snicket could be taken for the author who has written the series. His name appears on the book covers, and at the end of each volume there is also his short biography and a photograph. There is even a companion book to the series which is supposedly Snicket's autobiography. However, the book's title is Lemony Snicket: The Unauthorized Autobiography (emphasis added), which immediately puts the reader on guard. His wariness is fully justified, as the "autobiography" is far from a coherent narrative. Instead, it is a collection of fictional reports, letters and documents, and the questions it raises are much more numerous than the answers it provides. Similarly, the biographies and photographs included in the thirteen main books are also quite unconventional: the former consist mainly of idiosyncratic details, while the latter always show Snicket as an indistinct silhouette without a face, usually seen from behind.

In fact, Lemony Snicket is a pseudonym used by Daniel Handler. For some time, when Handler gave interviews about $A$ Series of Unfortunate Events, he always did so as Lemony Snicket. Consequently, during meetings with readers, he introduced himself as Snicket's agent, and explained that Snicket himself could not come because he had been bitten by a giant insect (Kirtley 2013). He thus maintained a sort of peritextual illusion of Snicket's existence as a real, separate person, which created an attractive sense of mystery, heightened by Snicket's facelessness and obscure mentions of him hiding from his enemies and mourning a dead lover, stated both in the peritext (e.g., the biographical notes at the end of each book), and in the narrative itself. At the same time, despite the insistence on his real existence, his elusiveness and eccentricity suggest his ontological status as a fictional construct which functions within the realm of the story. 
Indeed, Snicket is also the narrator, and he is so idiosyncratic that the phrase "Lemony Narrator" has been coined after him. ${ }^{3}$ He frequently stops the flow of the story to comment on his own narrative. His trademark phrase is "a word which here means:" he never stops inserting glosses which, if taken at face value, should explain the words or expressions that he uses, as if he wanted to educate his readers. However, this educational aspect becomes doubtful when we look at some explanations which are not very informative, or can even be misleading.

The word "briskly" here means "quickly, so as to get the Baudelaire children to leave the house."

The Bad Beginning (1999), 18

Hector did not rise to the occasion, a phrase which here means "continued to sit in his folding chair with his eyes cast downward" (...)

The Vile Village (2001), 117

(...) contemptuously, a word which here means "while trying to scratch his nose within the confines of the bird cage."

The End (2006), 142

The excerpts above contain all formal indicators of definitions, such as quotation marks or the introductory phrase "the word/phrase X here means." And yet, they are not true definitions; they do not explain the linguistic meaning of the word or phrase which could be found in a dictionary, but rather provide a description of the context in which they appear. In the first example, the description is additionally suffused with subtle irony, when the narrator unveils the true intentions of a character who wants to "get the Baudelaire children to leave the house." Such explanations draw the reader's attention to the text's ontological status as a text, since the words and expressions are defined not in reference to external, objective linguistic reality, but to the specific linguistic microcosm of the narrative. The narrator also subverts the expectations that the reader has of the definition genre, producing a parodic, comic effect which culminates in examples like the tautology below:

(...) futile, a word which here means "filled with futility."

The Wide Window (2000), 49

A term used on TV Tropes, meaning "a narrator who tells the story from a third-person perspective, in an eccentric, bizarre, or otherwise unconventional style". TV Tropes is a pop-culture wiki dedicated to describing tropes in culture, and as such is an interesting example of hobbyist literary (and other) criticism. 
Apart from the comic effect, such excerpts require the reader to question the narrator's authority. The narrator is not a savvy adult who explains the world to an ignorant child. Since he gives absurd, redundant or misleading explanations, he cannot be trusted. As a result, the reader is far from passive: his task is to identify the explanations as absurd, redundant or misleading, and interpret them accordingly, admitting their ironic, subversive nature. While the narrator seems to give meaning to the text by inserting the glosses, it is really the reader who creates meaning in the act of reading. In this act, he is given autonomy, which is all the more important if we consider that $A$ Series of Unfortunate Events is a children's book series. Traditionally, the difference between the storyteller and the receiver is even more profound in this genre than in general fiction, since the obvious inequality between the one who speaks and the one who listens is strengthened by the advantage of age, experience, and power that an adult has over a child. Here, on the other hand, it is the child who is given power that the adult renounces.

It is worth noting that the narrator's glosses draw the reader's attention not only to the novels' linguistic microcosm, but also to the narrative structures and tropes that appear in them:

In the case of the next three chapters (...) the story is organised simultaneously, which means that you do not have to read the chapters in the order in which they appear.

The Penultimate Peril (2005), 83

"There is a type of situation, which occurs all too often and which is occurring at this point in the story of the Baudelaire orphans, called "dramatic irony." Simply put, dramatic irony is when a person makes a harmless remark, and someone else who hears it knows something that makes the remark have a different, and usually unpleasant, meaning. (...) Dramatic irony is a cruel occurrence, one that is almost always upsetting, and I'm sorry to have it appear in this story (...).

The Reptile Room (1999), 32

However, despite the focus on the language and on the narrative structures, the narrator insists that the story he tells is not made up, but true. Instead of emphasising and exploring his creative power, he renounces it, presenting himself as a mere reporter, just like Handler presented himself as a mere agent.

Handler's excuses about Snicket having been bitten by a giant insect were easy to see through; Snicket's insistence on the story's factual, and not fictional, nature, is just as easy to challenge. Contrary to how he presents his work, he would not have been able to reconstruct the details of events and conversations only with newspaper clippings and circumstantial evidence. Even without taking into consideration the glaring lack of realism, ${ }^{4}$ the reader will not believe the narrator simply out of perversity. The

4 One of the most obvious examples would be the character of Sunny who, though still a baby, is surprisingly communicative. Consider this passage from The Slippery Slope (2003), 226: "“Ga ga goo goo,' Sunny said, which meant 'I won't be caught, because they think I'm only a helpless baby.'” 
more the storyteller insists on telling the truth, the more we suspect him of lying (Kahan 2009). Similarly to the case of pseudo-definitions, there is a discrepancy between what the narrator says and what the reader understands. Again, the narrator is unreliable, and power is on the reader's side.

What is more, by renouncing the authority of the story's creator, the narrator presents himself almost as the story's victim: "It is my sad duty to write down these unpleasant tales," he states on the back cover of The Bad Beginning (1999). He repeatedly says that the books about Baudelaires are full of sadness and despair, and that he would love to write them differently, but he cannot change the truth. He cannot influence the story, which is completely beyond his control. He must be the narrator, even though it fills him with grief. Lamenting about the story's tragic twists and confessing that he suffers from bad dreams and crying fits, he is powerless and almost hysterical.

The reader, on the other hand, is free to put the book down. Snicket never fails to encourage him to do so. The very first sentence of the entire series is: "If you are interested in happy endings, you would be better off reading some other book" (The Bad Beginning [1999], 1). The effect is twofold. First, in accordance with the forbidden fruit logic, by being persuaded to stop, the reader is actually drawn in. Second, it is the reader who is invested with power. The traditional power dynamic between the narrator and the reader (and between the adult and the child) is subverted.

However, Lemony Snicket's status is even more complicated. He is not only the alleged author and the reluctant narrator, but also a character. From the very beginning, he mentions details from his own life in the narrative. As the series progresses, it is suggested that Lemony Snicket knew the Baudelaires' parents and belonged to the mysterious V.F.D. organization whose secrets the protagonists try to uncover. However, even though he turns out to belong to the diegetic world, Lemony Snicket himself never enters the story, with one possible exception. In the penultimate book, the protagonists meet a stranger who offers them help, but they decide to politely decline it. The man accepts their decision and leaves to never appear again. Although it is not stated explicitly, it is possible that the man is, in fact, Lemony Snicket, who once again refuses to interfere with the lives of his protagonists. Instead of taking control of them, he lets them retain their autonomy, just like the reader retains his.

As an author, narrator and character, Lemony Snicket transgresses the boundaries between the extradiegetic and the intradiegetic (See Figure 1). He is, therefore, an excellent example of metalepsis, a phenomenon frequently associated with metafiction (Kahan 2009). Interestingly, however, he distances himself from all three levels of his ontological status: as the author, he fails to come to meetings with fans; as the narrator, he claims to have no power over his story and seems confused by the very language he uses; and as a character, he refuses to act within the story. 
Pobrane z czasopisma New Horizons in English Studies http://newhorizons.umcs.pl Data: 26/04/2023 05:19:51

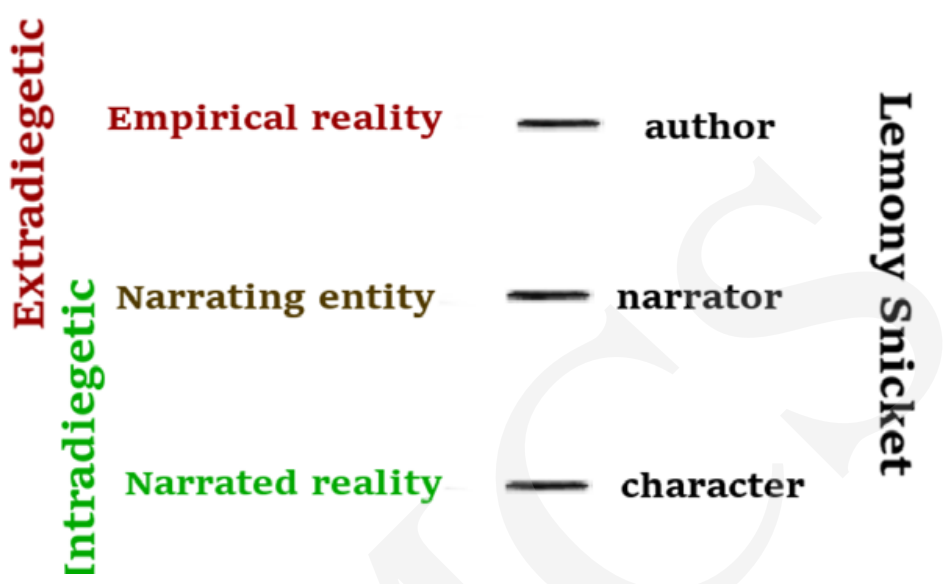

Figure 1. Metaleptic ontological status of Lemony Snicket

\section{Adapting Metafiction}

A Series of Unfortunate Events has been adapted twice: first, as a film directed by Brad Silberling and released in 2004, and more recently as a TV series produced and distributed by Netflix, and written mostly by the novels' author, Daniel Handler. The first season of the TV series was released in January 2017 and covers the first four volumes. As mentioned, this paper focuses on the way in which the metafictional aspects of the books were transposed into a new medium in the most recent adaptation, although it also includes a reference to the 2004 film for the purposes of comparison.

If we consider that a metafictional narrative consists of writing about writing and reading, then a metafictional film or TV series should be a show about showing and watching. The viewer's attention should be drawn to the TV series' nature as a fictional, created story. Accordingly, in the Netflix rendition of A Series of Unfortunate Events, there are several instances of characters breaking the fourth wall. Most importantly, in the last episode, the word "season" is used repeatedly in dialogue to designate periods of time. For example, the villain asks one of the protagonists, "Haven't you learned anything this year... week... season?" (The Miserable Mill: Part Two 2017, 00:29:27-00:29:29). "Year" is a rational, intradiegetic period of time during which the events of the series could have taken place. "Week," on the other hand, is extradiegetic: due to Netflix's practice of making entire seasons of its series available at once, it is probable that the viewer has watched the eight episodes of $A$ Series of Unfortunate Events' first season in so many days. His adventure with the Beaudelaire orphans has, therefore, lasted around a week, and the villain seems to underscore this very fact. The metafictional aspect is immediately made even stronger thanks to the use of the word "season," which clearly points to the story's nature as a TV series. 
Another instance of breaking the fourth wall is the following very memorable, if a bit unsettling, scene in the third episode.

Uncle Monty: Now, let's eat quickly, everyone, we don't want to be late to the movies. (...)

Count Olaf: In all honesty, I prefer long-form television to the movies. It's so much more convenient to consume entertainment from the comfort of your own home. (He looks straight at the camera for three seconds, gives a hint of a smile, and looks back to Uncle Monty).

The Reptile Room: Part One 2017, 00:27:40 - 00:28:19

The scene resumes as if nothing has happened, but the message has already reached the viewer. The show has admitted and underscored its status as a show, mostly for the purpose of humour, while at the same time boasting its alleged superior status and valorising the viewers' experience by suggesting that Internet TV series are better than going to the cinema. Nevertheless, the mocking comedy is combined with a sort of uneasiness; the three seconds of silence when Count Olaf stares with stone-faced intensity straight at the camera - straight at the viewer - are met with laughter that is more nervous than wholehearted. By contrast, in Lemony Snicket's novels, characters never venture beyond the narrated reality, and metafictional aspects of their dialogue are never as explicit as in this scene. Consequently, the breach of the barrier between the intradiegetic and the extradiegetic is all the more unsettling because it is a character who commits the breach.

The uneasiness is much less pronounced when the TV series adapts the flagship element of the novels: the narrator figure of Lemony Snicket and his metaleptic nature. The opening credits state that the series is based on the books by Lemony Snicket (although it is Handler who is credited as the scriptwriter), which preserves the suggestion of his "real-world" existence. Within the story, Snicket is straddling two worlds: the world of characters and the world of the viewer. He is often on the screen with other characters, but he is never in the scene. He may take a tram ride with them, he may be sitting on a chair in the same room, or he may even be standing in a crowd of mill workers, wearing the same uniform as them, but he never interacts with characters, and they do not even notice him. He is only to be seen by the viewer, whom he addresses directly, using the characteristic style of the books' narration. When he steps in, characters go silent and the action slows down, so that he can comment on the story, reciting passages that are often taken almost word-for-word from the novels. He also encourages the viewer to stop watching, and says with resignation that "this is how the story goes," thus denying its fictionality and implying its predetermined, unchangeable course.

However, despite the fact that most of his dialogue is shifted verbatim from the books, there are some important differences in the very nature of the adapted Lemony Snicket. The first, obvious one is that Lemony Snicket now has a face; the other, that he is no longer a writer. Interestingly, both of these traits distinguish him from the Lemony Snicket in the 2004 film, in which he always appeared with his face in the shadow, typing on a typewriter in a dark room (thus completely detached from the world of 
the characters). In the TV series, he is more visually oriented: no longer a writer, he resembles a weather anchor or another authoritative figure reminiscent of David Attenborough pointing to interesting specimens of fauna. Unlike the book Snicket, he is not afraid to show his face, even though he does have enemies that he flees. He is also much less depressed as the narrator of the books. The actor's (Patrick Warburton's) entire body language suggests calm, composure, self-control and trustworthiness. He has the same sombre and melancholic attitude as the book Lemony Snicket, but without the latter's occasional emotional outbursts. Unlike the powerless book Snicket, he is a man the viewer wants to trust.

Even when he admits his powerlessness, it does not have the same impact as in the novels. In popular imagination, a novel is often perceived as a work of a single author, and the narrator as the sole entity shaping the story. ${ }^{5}$ By contrast, a TV series is never considered an opus of a single person. Its status as a collective work (Hendrykowski 2013, 270) is emphasised in the opening credits, which list the scriptwriter, producer, actors, editor, and photography director, to name only a few. Evidently, the credits also list the actor playing Lemony Snicket, which reduces him to another character, and slightly undermines his metaleptic nature. True, he is still the narrator, but he is not the only storyteller. A film is a multi-track medium, and such visual factors as the performance of other actors or the design of sets are also crucial for the final effect. As demonstrated above, the TV series characters are more likely to break the fourth wall than their book counterparts. They also have been given visible form and audible voice. No longer do they depend on the narrator allowing them to speak; they co-create the story on almost equal terms.

Another example of reducing Snicket's sovereignty over the intradiegetic world is the opening song. Its lyrics ("Look away, look away (...) This show will wreck your evening, your whole life, and your day / Every single episode is nothing but dismay"6) take over to some extent the book Snicket's warnings about the depressing content of the books and his advice not to read them. The closest equivalent of the song can be found on the novels' back covers, always featuring a warning letter to the reader; all those peritextual letters, however, are dutifully signed by Lemony Snicket. By contrast, the Lemony Snicket in the TV series does not enter into the peritext. He never oversteps the borders of the episode proper, limited by the end of the opening song on one side, and by the beginning of the closing credits on the other.

Consequently, the Lemony Snicket in the TV series has less power at the outset. As a result, his renunciation of that power does not give an equally strong impression as in the books, especially when the alleged powerlessness is contradicted by his attitude and actions, particularly in one key scene of the TV series that merits a more detailed discussion.

5 The actual accuracy of that view is of little importance for our discussion; what matters is the perception.

6 E.g. The Bad Beginning: Part One 2017, 00:00:06-00:00:20. 


\section{Viewer's Fatal Deception}

Throughout the entire season, the story of the Baudelaire orphans interweaves with the scenes presenting two adults escaping from a prison in which they have been confined by their enemies. The scenes form an arc that is completely absent from the novels and are presented exclusively through visual storytelling and characters' dialogue, with no interferences of the narrator. As a result, the viewer is free to interpret those scenes on his own. Since the two imprisoned adults often mention that they have to return to their children as soon as possible lest they worry, the most obvious conclusion is that they are the Baudelaires' parents.

While most obvious, it is also most disconcerting for the viewer, especially for the one who is familiar with the original novels. The Baudelaires' parents being alive goes against the narrative's most basic premise: the finality of death, the impossibility of a happy reunion, and the futility of hoping for a return to the childhood world in which "all is right" (to quote the utopian ending of J.K. Rowling's Harry Potter series: Rowling 2007, 607). The new arc of the prison-breaking adults is surprising for the readers-turned-viewers, putting them on edge and providing fresh food for thought, while at the same time engaging them in an intertextual and metafictional game of expectations. The viewer cannot but wonder how the story continues, or rather, how its writers have decided to structure it. Will the Baudelaire children reunite with their parents in the last episode? Will the resolution be put off to the next season? Will all hopes be dashed when the adults die after all, sacrificing themselves in a climactic battle? The viewer is provoked, so to speak, to ask those questions, and the majority of them require him to think about the story in terms of narrative structure and tropes. It is his general communication and narrative skills that come into play, as well as the specific extradiegetic knowledge of the series' predilection for the unfortunate which seems to clash with the appearance of the resourceful prison-breaking adults, thus creating tension.

The puzzling arc culminates in the penultimate episode, ${ }^{7}$ in a sequence of scenes in which the children, working at the mill at that time, are told that they have visitors. They do not know who it might be, but the viewer does (or rather, thinks that he does), because he has seen all the scenes with the adults. As a result, the viewer is more hopeful than the characters. In the books, on the other hand, it is usually the opposite: the protagonists hope for something to happen, but the reader usually knows in advance that their situation is hopeless. By anticipating the unhappy resolution, the narrator puts the reader in the situation of "dramatic irony" that Lemony Snicket explains in the second book of the series. ${ }^{8}$ The difference lies not so much in the reader's or viewer's prior awareness of a plot element as in the nature and outcome of his expectations: the reader expects the worst, and the worst does happen; the viewer expects the best, but the best does not happen.

Having been told that they have visitors, the children approach a large yellow door a "very fancy door," as it is called by another character. The phrase has its own special

\footnotetext{
The following discussion concerns The Miserable Mill: Part One 2017, 00:38:50-00:40:15.

8 Cf. the quotation above.
} 
meaning for the viewers familiar with the novels. The first letters of the three words form the acronym V.F.D., which refers to the mysterious fire-fighting organization whose secrets the protagonists try to uncover from the fifth book onwards, with varying success. One thing they learn for certain: practically everything related to the V.F.D. bears the same acronym, from its headquarters in the Valley of Four Drafts, to such inventions as Vernacularly Fastened Door and Volatile Fungus Deportation. The reader quickly becomes (overly) sensitive to all phrases beginning with the appropriate letters.

The first four books do not mention the V.F.D., simply because the author did not yet think of the idea at that stage; its introduction in later volumes actually leads to some inconsistencies. The TV series makes the V.F.D. a more integral part of the world from the very beginning, repeatedly hinting at the organization's existence and activities, as well as inserting numerous V.F.D. phrases in otherwise innocuous dialogue, like a market trader selling "very fresh dill." However, the fact that V.F.D. refers to the mysterious organization is not revealed, so the characters, as well as viewers unfamiliar with the novels, have no way of recognising those phrases, unlike a viewer who has read the novels and thus can interact with the series on a different, intertextual level, noticing and cherishing all of the V.F.D. mentions.

Naturally, for such viewers, the fact that the protagonists approach the "very fancy door" to meet their visitors infuses the scene with additional gravity and meaning. Again, the viewer knows more than the characters: not only is he sure that the Baudelaires' parents are alive and looking for them, but also he has just identified an element related to the mysterious V.F.D.

As the children approach the door to the rhythm of build-up music, the adult couple, nervous, yet hopeful, walk toward an identical yellow door which the viewer identifies as the other side of the same door. The adults look at each other and open the two leaves of the door in a dramatic gesture - just to walk into a house that has nothing in common with the mill where the protagonists are still waiting in front of their door. When the latter opens, bright light spills in as if in a parody of revelation, and the viewer can indistinctly see the silhouettes of the story's two villains before Lemony Snicket himself steps into the scene, grabs the camera, turns it away from the door and says: "I beg you, turn this programme off now. Imagine this story has a happy ending."

The viewer experiences a double shock. First, until the very last moment of a lengthy and suspenseful sequence of scenes, he is led to believe that the very fancy door seen by the children and the very fancy door to be opened by the adults are one and the same. The subsequent revelation to the contrary is a very powerful plot twist, whose force is even strengthened by Lemony Snicket's sudden intervention. The viewer is brutally reminded that he is watching a TV series. He is suddenly made aware of the fact that he has been manipulated by clever editing and tricked by his own brain.

The human brain is trained to construe the observed phenomena and to build relationships between them (even if, from the objective standpoint, there are none). Visual storytelling in film makes use of that tendency: footage is edited in such a way as to suggest a flowing narrative, even if the individual scenes were actually shot days or weeks apart. 
In a broader sense, the human search for meaning can be summarised as trying to explain the world by telling stories. Storytelling is the most basic cognitive activity reflected in the phrase homo narrans and underscored by metafictional prose. As stated above, the story's meaning is created through the receiver's interpretation, which implies a certain autonomy on the latter's part. However, in this sequence of the TV series, the viewer's interpretation is proven to be wrong, which seems to undermine and reduce his autonomy.

The viewer still retains his independence when he is given the opportunity to abandon the story. In that respect, Lemony Snicket's intervention is an equivalent of the book narrator's retardations: the frequent moments when he puts the plot on hold and persuades the reader to imagine a happy ending for the story and read something else instead. In the TV series, however, the effect is much more powerful simply because of its visual character. It would be difficult to imagine a more complete and more sudden breaking of the fourth wall, save for Lemony Snicket actually emerging from the screen into the empirical, physical world. Grabbing the camera is almost an act of violence, akin to grabbing the viewer's head and forcing him to look in the desired direction. It does not suggest the narrator's impotence; quite the contrary, he has total control over the way in which the story unfolds and over what the viewer sees.

\section{The Issue of the Receiver}

Before the closing remarks, a comment is needed regarding an issue raised in the discussion above. For a viewer familiar with the books, the TV series holds more meaning and lends itself to an intertextual, metafictional interpretation. The audience of the TV series is not restricted to children; on the contrary, it is safe to assume that a large part of its viewers are young adults. ${ }^{9}$ The reader-turned-viewer is often a young adult who has read the novels in childhood, and now revisits the series out of nostalgia or genuine liking. ${ }^{10}$ Older viewers are also usually more experienced when it comes to recognising narrative tropes, so it is more probable that they will fully appreciate the metafictional qualities of the series.

Even though this paper has "children's literature" in its title, it should be noted that the readership of $A$ Series of Unfortunate Series is not limited to children, either. Some of the allusions, themes, or the metafictional aspects can only be fully appreciated by a more seasoned reader. Nevertheless, a child can still enjoy the series, and find gratification in engaging with a story that does not hesitate to confront him with difficult words and unhappy endings, treating him "like an adult." A return to A Series of Un-

9 Unfortunately, no statistics for the show are available, but according to a survey conducted in the US (https://www.prnewswire.com/news-releases/netflix-is-now-preferred-tv-viewingsource-for-all-demographic-groups-300270704.html), Netflix is the main platform for watching TV shows for 39\% teens (13-17 y.o.), 51\% young Millennials (18-24 y.o.), and 34\% older Millennials (25-34 y.o.).

10 As evidenced by the fan forum "667 Dark Avenue": http://asoue.proboards.com/ 
fortunate Events when one is actually an adult can be just as satisfactory, if not more, as the reader discovers new meanings that eluded him in the past. Obviously, A Series of Unfortunate Events is hardly the only example of literature with a double reader; in fact, it is a well-known paradox of children's literature that although the genre is defined by being addressed to children, it can often be enjoyed just as much, if not more, by adults. ${ }^{11}$ Sometimes even literature intended primarily for adults (like $17^{\text {th }}$-century French fairy tales) masquerades as stories for children, revelling in the sense of wonder or the seeming naiveté the genre offers.

In the case of the TV series, the two receiver categories of adults and children intersect with the categories of viewers familiar and unfamiliar with the source text. Readers-turned-viewers are more likely to be young adults, simply because of the time that has elapsed since the books' publication.

Since an adaptation is always a palimpsest (to borrow Genette's [1982] metaphor) and is always determined to some extent by its link with the source text with which it forms a bi-text or a poly-text (Hendrykowski 2013, 269), it is not surprising that at least some of the tension in the TV series stems from its inherent intertextuality, requiring the knowledge of the novels. Younger viewers and those who have not read the novels can still find the series enjoyable, but many of its meanings and implications will only be explored and appreciated by adult readers-turned-viewers. The "very fancy door" plot twist discussed extensively above will probably be more striking to them than to the less seasoned viewers, and even though it undermines the receiver's autonomy, it also admittedly makes the story more surprising and more interesting to those who already know the novels' plot. It could even be argued that the plot twist has been conceived with the more savvy receiver in mind.

\section{Conclusion}

The adaptation of a metafictional book series creates a new intertextual (and thus metafictional) layer of storytelling, whose interpretation depends chiefly on the viewer's knowledge and experience. The metafictional status of the adaptation is necessarily different and possibly more complex than that of the primary text. Additionally, the transition to a more visual medium in the case of $A$ Series of Unfortunate Events creates an interesting paradox of Lemony Snicket. On the one hand, he has to renounce a part of his power as the narrator due to the visual nature of the new medium and its obviously shared authorship. On the other hand, however, the power that he does keep is exerted with greater authority and vigour than in the novels. Thus, the very transition from a medium governed by words to a medium governed by images has led to a slight shift in the manifestation of one of the series' metafictional aspects.

11 As has been observed by many scholars, i.a. Douglas 2006. 


\section{References}

\section{Referenced texts}

667 Dark Avenue, fan forum. http://asoue.proboards.com/. Accessed April 25, 2017.

Andrew, Dudley. 1984. Concepts in Film Theory. Oxford-New York-Toronto-Melbourne: Oxford University Press.

Austin, Sara. 2013. "Performative Metafiction: Lemony Snicket, Daniel Handler and The End of A Series of Unfortunate Events." The Looking Glass: New Perspectives on Children's Literature 17, no.1. http://www.the-looking-glass.net/index.php/tlg/article/view/387.

Boozer, Jack. 2008. "Introduction. The Screenplay and Authorship in Adaptation". In Authorship in Film Adaptation, ed. Jack Boozer, 1-30. Austin: University of Texas Press.

Chanady, Amaryll. 1988. "Une métacritique de la métalittérature: quelques considérations théoriques". Études françaises XXIII, no. 3, 135-145.

Currie, Mark. 1995. "Introduction.” In Metafiction, edited by Mark Currie, 1-18. New York: Longman Publishing.

Douglas, Virginie. 2006. "Traduire l'intertextualité en littérature pour la jeunesse: le cas de Stalky \& Co. de Rudyard Kipling.” Palimpsestes 18. doi:10.4000/palimpsestes.563.

Genette, Gérard. 1982. Palimpsestes: La littérature au second degré, Paris: Seuil.

Hendrykowski, Marek. 2013. "Intertekst w adaptacji filmowej”. Images 21-22, 266-272.

Hutcheon, Linda. 1984. Narcissistic Narrative. The Metafictional Paradox. New York and London: Methuen University Paperback.

Kahan, Michèle Bobobza. 2009. "Métalepse et image de soi de l'auteur dans le récit de fiction." Argumentation et Analyse du Discours 3. doi:10.4000/aad.671.

Kirtley, David Barr (2013), "Interview: Daniel Handler (a/k/a Lemony Snicket)”, Lightspeed 32. Accessed April 25, 2018. http://www.lightspeedmagazine.com/nonfiction/interview-daniel-handler-aka-lemony-snicket.

Rowling, J. K. 2007. Harry Potter and the Deathly Hallows. London: Bloomsbury.

Scholes, Robert. [1970] 1995. "Metafiction.” In Metafiction, ed. Mark Currie, 21-38. New York: Longman Publishing.

Snicket, Lemony. 1999. The Bad Beginning. New York: HarperCollins.

Snicket, Lemony. 1999. The Reptile Room. New York: HarperCollins.

Snicket, Lemony. 2000. The Wide Window. New York: HarperCollins.

Snicket, Lemony. 2001. The Vile Village. New York: HarperCollins.

Snicket, Lemony. 2003. The Slippery Slope. New York: HarperCollins.

Snicket, Lemony. 2005. The Penultimate Peril. New York: HarperCollins.

Snicket, Lemony. 2006. The End. New York: HarperCollins.

TV Tropes. n.d. "Lemony Narrator." Accessed October 27, 2017. http://tvtropes.org/pmwiki/ pmwiki.php/Main/LemonyNarrator.

Waugh, Patricia. 1984. Metafiction: The Theory and Practice of Self-Conscious Fiction. New York: Methuen. 
Pobrane z czasopisma New Horizons in English Studies http://newhorizons.umcs.pl Data: 26/04/2023 05:19:51

\section{Referenced films}

The Bad Beginning: Part One. 2017. Directed by Barry Sonnenfeld. Video streaming available on https://neflix.com. Accessed January 2017.

The Miserable Mill: Part One. 2017. Directed by Bo Welch. Video streaming available on https://neflix.com. Accessed January 2017.

The Miserable Mill: Part Two. 2017. Directed by Bo Welch. Video streaming available on https://neflix.com. Accessed January 2017.

The Reptile Room: Part One. 2017. Directed by Mark Palansky. Video streaming available on https://neflix.com. Accessed January 2017. 